\title{
Research on the Coupling between Agricultural Heritage and Tourism Industry: A Case Study of Jasmine and Tea Culture in Fuzhou
}

\author{
Yunmeng Ma*, Geying Lai \\ School of Geography and Environment, Jiangxi Normal University, Nanchang 330200, Jiangxi Province, China \\ *Corresponding author: Yunmeng Ma, maymengn@163.com
}

\begin{abstract}
The integration of agricultural heritage and tourism industry contributes significantly to regional heritage protection, rural revitalization, and cultural inheritance. Based on the coupling coordination degree model, a quantitative research was conducted to study the integration of agricultural heritage in terms of the jasmine and tea culture system in Fuzhou with the local tourism industry. The results showed that both the development of Fuzhou's jasmine and tourism industries have advanced significantly and are currently leading in the country. However, they are not developing at the same pace. The results also showed that the coordination degree between Fuzhou's jasmine and tourism industries have increased in recent years, with deepened mutual effects and improved coordination. Moreover, the coupling coordination degree has been rising over the past 13 years, with the coupling coordination level transforming from "extreme disorder" to "quality coordination," demonstrating a slow integration progress of Fuzhou's jasmine with the tourism industry at the early stage, but a sound development momentum at the later stage.
\end{abstract}

Keywords: Agricultural heritage; Tourism; Coupling coordination degree model; Jasmine and tea culture system in Fuzhou Publication date: October 2021; Online publication: October 29, 2021

\section{Introduction}

Agricultural heritage is distinguished from common cultural heritage and natural heritage because it is a unique land-use system with agricultural landscape and farming culture formed by long-term coevolution and dynamic adaptation between rural areas and their surrounding environment. Agricultural heritage is a special kind of living heritage ${ }^{[1]}$. Since the launching of Globally Important Agricultural Heritage Systems $(G I A H S)$ by the Food and Agriculture Organization in $2002^{[2]}$, protecting agricultural heritage while developing tourism has been one of the top concerns in the academic community. As a matter of fact, the conservation of agricultural heritage has never been isolated. Instead, it always takes root in a certain economic and social development context or condition ${ }^{[3]}$. In 2015, the management measures found in the Nationally Important Agricultural Heritage issued by China's Ministry of Agriculture and Rural Affairs provided guidance for heritage sites to step up the exploitation, protection, transformation, and innovation of agricultural resources with local characteristics, developing new business forms such as leisure tourism, cultural experience, and popular science education to drive local cultural, economic, and social development ${ }^{[4]}$. Thereafter, the Rural Revitalization Strategic Plan (2018-2022) that was put forward proposed to observe the trend of consumption expansion and upgrading among urban and rural residents while combining local resources in the discovery of multiple functions and values in agriculture and rural areas. Statistics have shown that the number of tourists participating in leisure agriculture and rural tourism increased from 720 million in 2012 to 3 billion in 2019, with a compound annual growth rate of up to $30 \%$. 
In the meantime, people's demand for tourism has transformed from pure material consumption to the experience of cultural diversity, thus providing a great opportunity to develop tourism with agricultural heritage ${ }^{[5]}$. Accelerating the integration of agricultural heritage and tourism industry promotes the demonstration and publicity of agricultural heritage, expands tourism boundary, advances tourism economy, and contributes to rural revitalization.

A review of recent research on agricultural heritage and related tourism development provides an overview of the hottest research topics in this sub-field, which include the significance of agricultural heritage development ${ }^{[6,7]}$, tourism development model ${ }^{[8-10]}$, tourism resource exploitation ${ }^{[11,12]}$, tourism impact ${ }^{[13]}$, and community participation ${ }^{[14]}$. Based on the literature review, it can be concluded that studies tend to involve the relationship between tourism development and a certain aspect of agricultural heritage sites, such as the economy or culture, yet a quantitative analysis is still lacking. Furthermore, up to this date, only a few scholars have looked into the jasmine and tea culture system in Fuzhou as an agricultural heritage. Dozens of papers involving jasmine and tourism in Fuzhou have been found over the past decades, most of which regarded tourism as a form of traditional agriculture. For instance, Yu Shuai ${ }^{[15]}$, Lin Lingjing ${ }^{[16]}$, Guo $\mathrm{Li}^{[17]}$, and Hou Yuting ${ }^{[18]}$ analyzed the status quo, problems, and future development of jasmine tourism in Fuzhou. Last but not least, as the core area of China's Belt and Road Initiative, Fuzhou's economic and cultural impacts can reach out to South Asia and Southeast Asia. Although Fuzhou has been listed as one of the "National Key Villages for Rural Tourism" by the Ministry of Culture and Tourism of China and the National Development and Reform Commission, the development of rural tourism projects is simple and superficial, lacking the unique local flavor. This is the reason for the urgent need of intervention and empowerment of agricultural heritage. Although it has been universally recognized by the academic community that cultural heritage and tourism are two major factors in tackling the challenges when developing rural areas, due to the late arrival of the concept, "agricultural heritage," only a few research exists in regard to its coupling development with tourism.

Based on the above analysis, a quantitative research with qualitative analysis has been conducted. The coupling coordination situation, achievement, and experience of agricultural heritage and the tourism industry have been explored and analyzed with an aim to promote the cultural inheritance as well as revitalize the tourism industry in rural areas. This research can help improve the management of agricultural heritage sites, raise economic benefits in agricultural heritage tourism, and promote conservation of the natural, cultural, and ecological aspects of agricultural heritage.

\section{Overview}

Jasmine tea is believed to have originated from Fuzhou, China. Jasmine is native to India and the Persian Gulf. During the Western Han Dynasty, the flower was introduced to China via the Land and Maritime Silk Routes and later took root in Fuzhou. The unique geographical conditions in the area were favorable to this type of flower. Fuzhou is located on the eastern coast of Fujian Province at the lower reaches of the Min River. In terms of geographic location, the city sits between $25^{\circ} 15^{\prime}-26^{\circ} 29^{\prime} \mathrm{N}$ and $118^{\circ} 08^{\prime}-120^{\circ} 31^{\prime} \mathrm{E}$. Fuzhou is traversed by the Min River, with Fuzhou Basin at the lower reaches, mountains and hills in the north, and plains in the south ${ }^{[19]}$. Fuzhou has a typical subtropical maritime monsoon climate, with an average annual temperature of $16-20^{\circ} \mathrm{C}$ and a sunshine duration of $1700-1980$ hours. The city has a frostfree period of 326 days, annual precipitation of $900-2100 \mathrm{~mm}$, and $77 \%$ average humidity. Heritage sites of Fuzhou's jasmine and tea culture system are located in six counties (cities, districts), Jin'an District, Cangshan District, Minhou County, Lianjiang County, Changle Municipal City, and Yongtai County, covering a land area of $3291 \mathrm{~km}^{2}$. In those regions, Jasmine flowers are mainly grown on alluvial plains and sandbanks along the Min River, while tea trees are raised in mountainous areas such as Gushan. 


\section{Methodology}

\subsection{Establishing the indicator system}

The coupling relationship between agricultural heritage and the tourism industry can be seen in two aspects. First of all, the favorable ecological environment, local ethnic culture, unique rural landscapes, quality agriculture varieties, sideline products, and health supplies are all important resources for developing tourism products as well as providing unique experience and health maintenance services. Secondly, developing the tourism industry, as an important approach to revitalizing agricultural heritage, drives local service industries with the needs of tourists, including food, travel, lodging, shopping, and entertainment. The economic benefits from the development further enable the conservation of local heritage and cultural inheritance. In addition, the higher the demand, the higher the need for labor. People would return to their hometowns to look for employment or start their own businesses, so the problem of insufficient agricultural inheritors can be solved. In the meantime, establishing famous brands which are well-recognized by the public while developing the tourism industry can attract the interest of tourists in agricultural heritage, encourage them to appreciate the rural areas, and to learn more about their current situations, history, and culture.

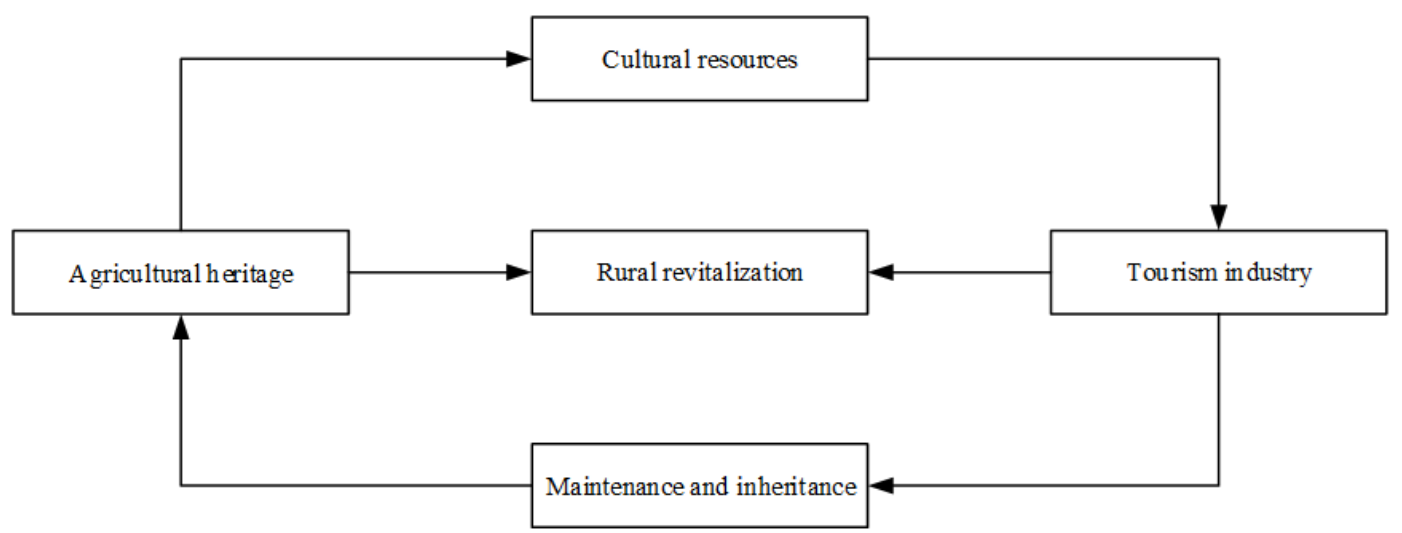

Figure 1. Construction and geometrical dimensions of specimens

Due to complicated factors involved when evaluating the two systems, an indicator system has been established for the jasmine and tourism industries in Fuzhou's agricultural heritage sites in compliance with the principles of scientificity, integrity, and data availability. Existing research results were used for the construction of the indicator system ${ }^{[20,21]}$. Firstly, the indicator system for Fuzhou's jasmine is based on the above analysis on coupling theory. Secondly, word frequency was counted by drawing the highfrequency index used in the China National Knowledge Infrastructure (CNKI) database on "agricultural heritage conservation and protection" in recent years and the Regulations on Jasmine Tea Protection in Fuzhou ${ }^{[22]}$ before seeking any expert opinions. The indicator system in Table 1 used the entropy weight method (EWM) to determine the weight. This was done because EWM can objectively calculate the index weight based on the index's degree of variation and would provide a basis for comprehensive evaluation of multiple indicators ${ }^{[23]}$. 
Table 1. Coupling coordination degree measurement system

\begin{tabular}{|c|c|c|c|c|c|}
\hline $\begin{array}{l}\text { Target } \\
\text { tier }\end{array}$ & $\begin{array}{l}\text { Tier } 1 \text { indicator } \\
\text { and weight }\end{array}$ & Tier 2 indicator & $\begin{array}{l}\text { Unit for Tier } 2 \\
\text { indicator }\end{array}$ & Nature & Weight \\
\hline \multirow{23}{*}{$\begin{array}{c}\text { A: } \\
\text { Jasmine } \\
\text { and tea } \\
\text { culture } \\
\text { system } \\
\text { in } \\
\text { Fuzhou }\end{array}$} & \multirow{4}{*}{$\begin{array}{l}\text { A1: Integrity of } \\
\text { natural elements } \\
(0.202)\end{array}$} & A11: Number of core conservation areas & / & Positive & 0.052 \\
\hline & & A12: Jasmine tea varieties & / & Positive & 0.051 \\
\hline & & A13: Biodiversity & Number of species & Positive & 0.044 \\
\hline & & A14: Area of tea plantation & Hectare & Positive & 0.055 \\
\hline & \multirow{3}{*}{$\begin{array}{l}\text { A2: Cultural } \\
\text { heritage }(0.194)\end{array}$} & A21: Number of tea craftsmen & l & Positive & 0.043 \\
\hline & & A22: Number of tea measure & I & Positive & 0.086 \\
\hline & & A23: Landmark buildings and titles of honor & I & Positive & 0.065 \\
\hline & \multirow{7}{*}{$\begin{array}{l}\text { A3: Production } \\
\text { sustainability } \\
(0.297)\end{array}$} & A31: Total tea production & 10,000 ton & Positive & 0.053 \\
\hline & & A32: Tea production value & 100 M yuan & Positive & 0.046 \\
\hline & & A33: Brand value & 100 M yuan & Positive & 0.045 \\
\hline & & A34: Number of tea factories and enterprise & l & Positive & 0.048 \\
\hline & & A35: Average export price & dollar/kg & Positive & 0.037 \\
\hline & & A36: Average price of jasmine tea & yuan $/ \mathrm{kg}$ & Positive & 0.032 \\
\hline & & A37: Per capita income of tea farmers & yuan & Positive & 0.036 \\
\hline & \multirow{5}{*}{$\begin{array}{l}\text { A4: Scientific } \\
\text { research } \\
(0.094) \\
\text { A5: } \\
\text { Governmental } \\
\text { policies }(0.087)\end{array}$} & A41: Number of patents & / & Positive & 0.043 \\
\hline & & A42: Research reports and papers & / & Positive & 0.051 \\
\hline & & A51: Conservation plans, policies, and regulations & I & Positive & 0.043 \\
\hline & & A52: Financial subsidies & yuan/mu & Positive & 0.044 \\
\hline & & A61: Water quality of Min River (Fuzhou section) & $\%$ & Positive & 0.017 \\
\hline & \multirow{4}{*}{$\begin{array}{l}\text { A6: Ecosystem } \\
(0.124)\end{array}$} & A62: Air quality & $\%$ & Positive & 0.026 \\
\hline & & A63: Comprehensive air quality index & $\mu g / m^{3}$ & Negative & 0.034 \\
\hline & & A64: Green coverage & $\%$ & Positive & 0.027 \\
\hline & & A65: Forest coverage & $\%$ & Positive & 0.020 \\
\hline \multirow{12}{*}{$\begin{array}{l}\text { B: } \\
\text { Impact } \\
\text { on the } \\
\text { tourism } \\
\text { industry }\end{array}$} & \multirow{2}{*}{$\begin{array}{l}\text { B1: Impact on } \\
\text { tourism } \\
(0.213)\end{array}$} & B11: Domestic travel & 10,000 & Positive & 0.116 \\
\hline & & B12: Inbound tourist arrivals & 10,000 & Positive & 0.097 \\
\hline & B2: Tourism & B21: Domestic tourism revenue & $100 \mathrm{M}$ & Positive & 0.148 \\
\hline & $\begin{array}{l}\text { revenue } \\
(0.21)\end{array}$ & B22: Inbound tourism revenue & 10,000 dollars & Positive & 0.062 \\
\hline & \multirow{3}{*}{$\begin{array}{l}\text { B3: Tourism } \\
\text { service } \\
(0.216)\end{array}$} & B31: Number of tourist hotels & / & Positive & 0.074 \\
\hline & & B32: Number of starred hotels & I & Positive & 0.079 \\
\hline & & B33: Number of hospital beds & I & Positive & 0.063 \\
\hline & \multirow{2}{*}{$\begin{array}{l}\text { B4: Tourism } \\
\text { industry } \\
(0.166)\end{array}$} & B41: Number of travel agencies & l & Positive & 0.087 \\
\hline & & B42: Number of tourist attractions & I & Positive & 0.079 \\
\hline & \multirow{3}{*}{$\begin{array}{l}\text { B5: Tourism } \\
\text { employment } \\
(0.195)\end{array}$} & B51: Number of travel agency employees & / & Positive & 0.048 \\
\hline & & B52: Number of tourist hotel employees & I & Positive & 0.065 \\
\hline & & $\begin{array}{l}\text { B53 Number of people working at tourist } \\
\text { attractions }\end{array}$ & I & Positive & 0.082 \\
\hline
\end{tabular}

Note: "Starred hotels" refer to hotels with more than two stars 


\subsection{Data source}

The time-series data collected in this research concern 35 indicators in Fuzhou from 2008 to 2020. The data were collected from the following sources: (1) statistical yearbooks and bulletins; among them, A61, A62, A63, A64, A65, B11, B12, B21, B22, B31, and B33 were from Fuzhou Statistical Yearbook and statistical bulletins concerning national economic and social development, whereas B32, B41, B42, B51, B52, and B53 were derived from Fuzhou Statistical Yearbook as well as Chinese Culture and Tourism Yearbook; (2) research reports, with A11, A12, A13, A23, A41, and A42 from Agricultural Heritage Research in China [24] as well as Rural Revitalization and Agricultural Heritage: Report on China Nationally Important Agricultural Heritage Conservation and Development (2019) ${ }^{[25]}$; (3) government official websites, with A14, A31, A32, A33, A35, and A36 from Fuzhou Agricultural and Rural Bureau; A21, A37, A51, and A52 from the Fuzhou Municipal People's Government website; A22 from Fuzhou Municipal Bureau of Culture and Tourism while A34 from Fuzhou Municipal Market Supervision and Administration Bureau. Besides, due to the wide time span covered, the latest version of the data was chosen in case of changes in statistical calibers or recalculations. The missing data of a few years were calculated based on the growth rates and the values of other years.

\subsection{Data analysis}

\subsubsection{Evaluation of the overall development level}

The data of the indicators shown in Table 1 were nondimensionalized with the normalized method. The data with opposite natures were processed into positives by using the calculation variables of SPSS to make them comparable. In this research, the linear weighting method was adopted to calculate the overall development level of the two systems, assuming $U_{1}$ as the overall development index of agricultural heritage and $U_{2}$ as the overall development index of the tourism industry. Formula (1) was used for calculation; wherein, $\mathrm{W}_{\mathrm{j}}$ represents the weight of each indicator, and $\mathrm{Z}_{\mathrm{ij}}$ represents the standardized value of each indicator.

$$
\mathrm{U}_{\mathrm{i}=1,2}=\sum_{\mathrm{j}=1}^{\mathrm{m}} \mathrm{W}_{\mathrm{j}} \mathrm{Z}_{\mathrm{ij}}
$$

\subsubsection{Coupling coordination degree model}

The coupling coordination degree model is often used to analyze coupling relationships. The basic concept behind the model is that a higher degree of synchronized development between two researched subjects refers to a greater coordination degree ${ }^{[26]}$. The coupling between agricultural heritage and the tourism industry was analyzed based on this model. Two evaluation models were involved in the calculation: coupling degree and coordination degree. The formula is as follows:

$$
\mathrm{C}=\left\{\frac{\mathrm{U}_{1} \mathrm{U}_{2}}{\left(\mathrm{U}_{1}+\mathrm{U}_{2}\right)}\right\}^{\frac{1}{2}}
$$

$\mathrm{C}$ refers to the coupling degree used to measure the level of synchronized development between agricultural heritage and the tourism industry. Higher $\mathrm{C}$ values stand for higher coupling degrees. The calculation results are listed in Table 2. 


$$
\begin{gathered}
\mathrm{T}=\alpha \mathrm{U}_{1}+\beta \mathrm{U}_{2}, \quad \alpha+\beta=1 \\
\mathrm{D}=\sqrt{\mathrm{T} \times \mathrm{C}}
\end{gathered}
$$

In formulae (3) and (4), $\mathrm{T}$ stands for the overall coordination index, representing the overall coordination level between the two researched subjects, while $\alpha$ and $\beta$ are weights to be determined. This research assumed that the tourism industry is not solely decided by the agricultural heritage. Therefore, this research has chosen 0.3 for $\alpha$ and 0.7 for $\beta$. D refers to the coordination index used to measure the degree of coordinated development between the two systems. Based on the values of $\mathrm{D}$, the coupling coordination has been classified into ten different levels ${ }^{[27]}$, as shown in Table 2.

Table 2. Classifications of coupling coordination degree

\begin{tabular}{lcc}
\hline Coupling state & Range & Coupling coordination level \\
\hline \multirow{3}{*}{ Budding } & $0.00 \sim 0.09$ & Extreme disorder \\
& $0.10 \sim 0.19$ & Severe disorder \\
\multirow{2}{*}{ Settling } & $0.20 \sim 0.29$ & Moderate disorder \\
& $0.30 \sim 0.39$ & Mild disorder \\
\multirow{2}{*}{ Steady } & $0.40 \sim 0.49$ & Border on disorder \\
& $0.50 \sim 0.59$ & Barely coordinative \\
\multirow{2}{*}{ High coupling } & $0.60 \sim 0.69$ & Primary coordination \\
& $0.70 \sim 0.79$ & Intermediate coordination \\
& $0.80 \sim 0.89$ & Excellent coordination \\
& $0.90 \sim 1.00$ & Quality coordination \\
\hline
\end{tabular}

\section{Analysis of results}

\subsection{Overall development level}

According to Table 3 and Figure 2, for the development levels of two systems, minimum values can be seen in 2008, the starting point of this research. Both values have been rising since then, among which, the overall development index for Fuzhou's Jasmine system, $U_{1}$, increased from 0.0273 in 2008 to 1.0017 in 2020, 37 times over twelve years. Seen from the broken line graph of the index, the overall development indexes for Fuzhou's jasmine and tea culture systems were relatively low between 2008 and 2011. The reason for that is because in the early stage, only minimal efforts were made to publicize agricultural heritage in addition to the low quality of most jasmine tea products and immature supporting environment. The rising momentum seen in the development index of Fuzhou's jasmine system was largely due to the government's policy support and guidance. At the 2014 Food and Agriculture Organization (FAO) conference in Italy, Fuzhou's jasmine and tea culture system was listed as an important global agricultural heritage. It was an event that marked the beginning of Chinese jasmine tea going abroad and reaching out to the world. In the same year, the local government formulated and implemented the Regulations on Jasmine Tea Protection in Fuzhou. Since 2016, suggestions on the protection and development of agricultural heritage have been frequently seen in China's No.1 central document. The overall development index of the tourism industry rose from 0.0149 in 2008 to 0.9132 in 2018, a 61-time increase without any decline over 10 years. This indicates that the tourism industry was developing rapidly, demonstrating a robust and sustainable development trend. From the values of the two indexes, the jasmine development 
index is greater than the tourism development index, indicating that Fuzhou's jasmine and tea culture system exerted a slightly greater impact on the tourism industry during the city's development.

Table 3. Coupling coordination degrees between Fuzhou's jasmine and tea culture system with the tourism industry

\begin{tabular}{ccccccc}
\hline Year & $\mathrm{U}_{1}$ & $\mathrm{U}_{2}$ & $\mathrm{~T}$ & $\mathrm{C}$ & $\mathrm{D}$ & Coupling coordination level \\
\hline 2008 & 0.0273 & 0.0149 & 0.0187 & 1.000 & 0.0187 & Extreme disorder \\
2009 & 0.0515 & 0.0770 & 0.0694 & 0.9220 & 0.0639 & Extreme disorder \\
2010 & 0.1127 & 0.1026 & 0.1057 & 0.9990 & 0.1056 & Severe disorder \\
2011 & 0.1703 & 0.1328 & 0.1441 & 0.9990 & 0.1439 & Severe disorder \\
2012 & 0.2890 & 0.2322 & 0.2492 & 0.9990 & 0.2490 & Moderate disorder \\
2013 & 0.3774 & 0.2931 & 0.3184 & 0.9970 & 0.3174 & Mild disorder \\
2014 & 0.5562 & 0.3728 & 0.4278 & 0.9890 & 0.4231 & Border disorder \\
2015 & 0.6359 & 0.4294 & 0.4913 & 0.9890 & 0.4859 & Border disorder \\
2016 & 0.7020 & 0.4960 & 0.5578 & 0.9920 & 0.5534 & Barely coordinated \\
2017 & 0.7895 & 0.5804 & 0.6432 & 0.9940 & 0.6393 & Primary coordination \\
2018 & 0.8622 & 0.7175 & 0.7609 & 0.9990 & 0.7602 & Intermediate coordination \\
2019 & 0.9304 & 0.8280 & 0.8587 & 1.0000 & 0.8587 & Excellent coordination \\
2020 & 1.0017 & 0.9132 & 0.9397 & 1.0000 & 0.9397 & Quality coordination \\
\hline
\end{tabular}

The rapid development and the rising momentum of Fuzhou's jasmine and tea culture system as well as the tourism industry owe largely to a few reasons. The first is the development of the tourism industry. In recent years, tourism demands have been exploding inside the city, and the tourism industry has been booming in nearly all districts. Fuzhou is a city well-known for its rich historical and cultural resources. As one of the national environmental protection demonstration cities, Fuzhou is endowed with abundant tourism resources. A three-dimensional transportation network, integrating the highways, railways, air, sea, and river, has been built to provide a strong support for tourism development. Over the past few years, the local government has been advocating "tourism development in the entire city," suggesting that supporting facilities should be improved, and rural revitalization as well as targeted poverty alleviation should be in line with tourism development, which have proven to be highly effective. The second is Fuzhou's conservation of agricultural heritage. Since 2008, Fuzhou's government has stepped up the subsidies for new jasmine plantations, encouraged jasmine enterprises to participate in exhibitions in over 20 cities and regions around the nation and actively take part in various exchanges as well as learning activities, regularly held scented tea culture festivals, tea craftsmanship, and tea master contests, as well as established and improved the agricultural heritage data monitoring system; all of which are concrete measures to protect and develop Fuzhou's jasmine and tea culture system. 


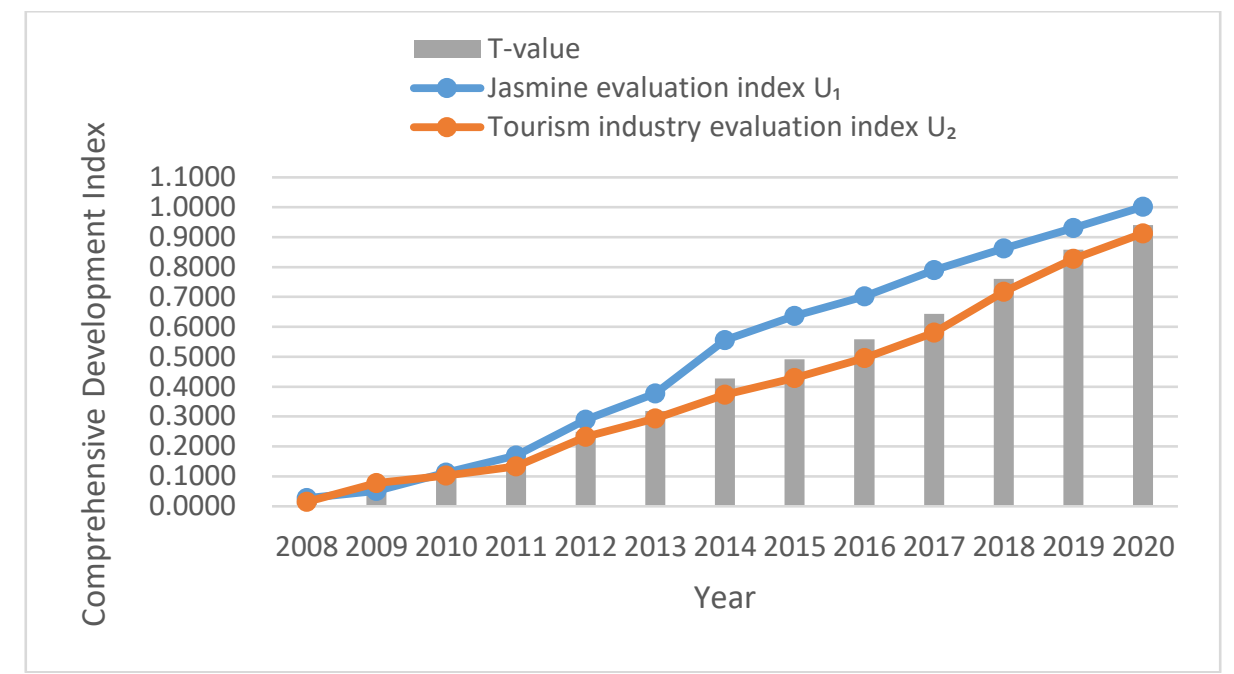

Figure 2. Overall development level of Fuzhou's jasmine tea agricultural heritage and the tourism industry

\subsection{Coupling degree and overall coordination index}

Statistical Package for the Social Sciences (SPSS) version 17.0 was used to analyze the correlation between Fuzhou's jasmine and tea culture system with the tourism industry. The correlation coefficient of the overall development level from 2008 to 2020 was 0.981 , indicating that Fuzhou's jasmine industry had potential to work with the city's tourism industry. As seen from Figure 3, the coupling degree of Fuzhou's jasmine and tourism industries demonstrated a steady growth with only a few fluctuations. The coupling degree dropped from 1.0 in 2008 to 0.922 in 2009, and rose back to 1.0 in 2019, with most figures reaching 0.900. The coupling was strong with only minor fluctuations, indicating that the jasmine and tourism industries in Fuzhou strongly interacted with and influenced each other. However, due to the different development pace of the two industries, the coupling degree exhibited some minor fluctuations. Besides, the overall coordination index $\mathrm{T}$ between the jasmine and tea culture system with the tourism industry in Fuzhou has risen significantly, from 0.010 in 2008 to 0.990 in 2020, a 99-time increase over 12 years, indicating the gradual improvement of the coordination between the city's jasmine and tourism industries in recent years, with deepened mutual influence and more coordinated actions (Figure 2).

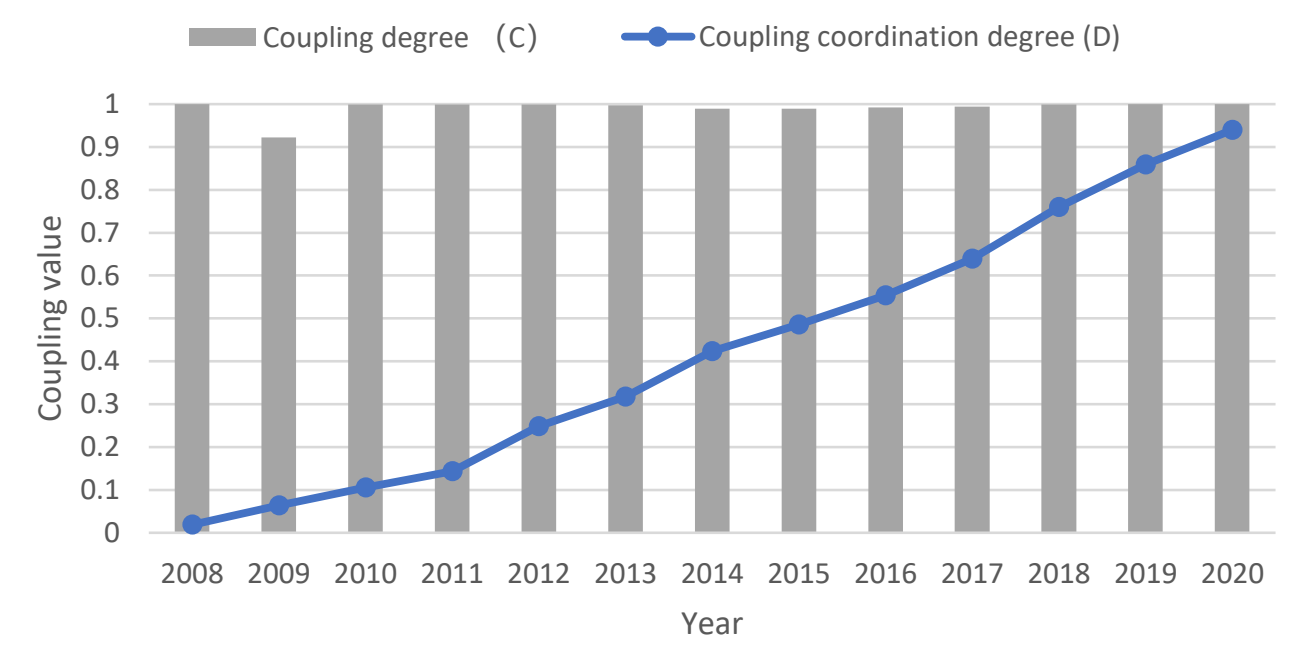

Figure 3. Coupling coordination degree between Fuzhou's agricultural heritage and the tourism industry 


\subsection{Coupling coordination degree}

From the results, the coupling coordination degree of Fuzhou's jasmine and tourism industries has increased from 0.0187 in 2008 to 0.9397 in 2020 . During the same period, the coupling coordination level has changed from "extreme disorder" in 2008 to "quality coordination" in 2020, moving up ten levels from "extreme disorder" (2008-2009), "severe disorder" (2010-2011), "moderate disorder" (2012), "mild disorder" (2013), "border disorder" (2014-2015), "barely coordinated" (2016), "primary coordination" (2017), "intermediate coordination" (2018), "excellent coordination" (2019), to "quality coordination" (2020), indicating that Fuzhou's jasmine and tourism industries have gradually merged over the past 13 years. The integration of the agricultural heritage with the tourism industry was proven highly effective and is scheduled to develop even further.

Chronologically speaking, the coupling between Fuzhou's jasmine and tourism industries can be divided into three stages. The first stage was the disorderly stage (2008 to 2015). During this stage, the coupling coordination level between the two industries had developed from "extreme disorder" to "border disorder," with a coupling coordination degree rising from 0.0187 to 0.4859 . The disorder between the two industries was so severe that it took the city eight years to shed off such a state. The reason for this is because of the late proposal of the concept "agricultural heritage." Although the regulations for jasmine tea protection in Fuzhou had been approved in 2014, the implementation took some time, which is why the policies were only being executed in the next few years. On the other hand, as an emerging form of tourism, agricultural heritage was still underdeveloped at that time, where systematic product series and effective coupling models were still lacking. Therefore, the systematic coupling between agricultural heritage and tourism was non-existent during that period, as demonstrated by the rare applications of agricultural heritage in tourism development.

The second stage was the primary coordination stage (2016 to 2018). The coupling coordination degree between Fuzhou's jasmine and tea culture system with the tourism industry increased from 0.5534 to 0.7602 , with the coupling coordination level changing from "barely coordinated" to "intermediate coordination." During this stage, tourism with agricultural heritage was emerging. It initially developed as Fuzhou municipal government was planning to build a jasmine tea industrial park and a global jasmine germplasm resource protection and innovation base. Tourism activities had been carried out at agricultural heritage sites by building tourist attraction sites, such as the 3A-level jasmine tea cultural and innovation park, six jasmine theme parks, and agricultural heritage museums. In Fuzhou, agricultural heritage started to merge with the city's tourism industry, exhibiting a trend of coordinated development.

The third stage was the advanced coordination stage (2019-2020). The coupling coordination degree between Fuzhou's jasmine and tourism industries increased from 0.8587 to 0.9397 , with the coupling coordination level changing from "excellent coordination" to "quality coordination." During this stage, Fuzhou began to attach great importance to developing tourism with agricultural heritage. The city has developed regional tourism resources with agricultural heritage, issued the "Nine Measures for Supporting Fuzhou's Jasmine Tea Industry," set up ecological agricultural heritage tea tourist areas, and supported over ten jasmine tea enterprises within the city. Through a series of commercial and promotional activities under the "Agricultural Heritage Tourism Festival," Fuzhou has achieved an even deeper integration of agricultural heritage with the tourism industry. The booming tourism also served as great publicity for agricultural heritage. Moreover, the income of local farmers have increased by taking advantage of this great opportunity. Back in 2019, the tourist attraction to agricultural heritage sites led to an income increase of 12,000 yuan for each household among 26,000 tea farmers and flower growers. Based on the current situation of the regional tourism industry, local villages have organized the jasmine harvesting festival and built agricultural heritage theme hotels, thereby forming a synergy between the agricultural industry and the tourism industry. Agricultural heritage has become an impetus for rural revitalization. Although the 
integration of the two industries has already reached its optimal state in 2020, it still has great potential for future improvement. The two systems should be constantly improved, and the coordination should be maintained at a quality level in order to further promote the economic development, ecological conservation, and cultural heritage.

\section{Conclusion}

By establishing an indicator system exclusively for Fuzhou's jasmine and tea culture system as well as the tourism industry, this study conducted a quantitative evaluation based on the coupling coordination model. The following conclusions can be drawn: (1) from 2008 to 2020, both the jasmine and tea culture system as well as the tourism industry in Fuzhou have advanced greatly and are currently leading in the country, but they do not advance in the same pace; (2) the coupling degree between Fuzhou's jasmine and tea culture system and the tourism industry steadily grew with only minor fluctuations, indicating that the jasmine and tourism industries in the city strongly interacted with and influenced each other; yet they do not share the same development speed; (3) the overall coordination index between Fuzhou's jasmine and tourism industries has been rising rapidly and continuously, indicating that the coordination degree of the two industries has seen a gradual increase in recent years, with deepened mutual effects and improved coordination; (4) the coupling coordination degree between Fuzhou's jasmine and tourism industries has been rising from 2008 to 2020, with the coupling coordination level changing from "extreme disorder" to "quality coordination"; the integration had a slow progress from 2008 to 2015 but during 2016 to 2020, the integration of the two industries was proved highly effective, and is scheduled to develop even further.

\section{Disclosure statement}

The authors declare that there is no conflict of interest.

\section{References}

[1] Min Q, 2013, Definition of Agricultural Heritage and Its Conservation and Development. Farmers' Daily, (004).

[2] Koohafkan P, Cruz MJD, 2011, Conservation and Adaptative Management of Globally Important Agricultural Heritage Systems. Journal of Resources and Ecology, 2(01): 22-28.

[3] Liu P, Gao Q, Xu W, 2008, An Analysis on the Relationship between Agricultural Heritage Conservation and Socio-Economic Development. Ancient and Modern Agriculture, 22(04): 89-98.

[4] Ministry of Agriculture and Rural Affairs of China, 2014, Management Measures for Nationally Important Agricultural Heritage. http://www.moa.gov.cn/

[5] Wu H, 2018, Analysis on Contemporary Innovation and Utilization of Outstanding Agricultural Heritage Systems. Agricultural History of China, 37(01): 115-121, 130.

[6] Min Q, Sun Y, Cheng S, et al., 2007, Primary Study on the Features and Development of GIAH's Tourism Resources. Economic Geography, 27(05): 856-859.

[7] Wu X, 2016, Research Review on Agricultural Heritage Systems and Its Tourism Development. China Training, 16(16): 29-30.

[8] Sun Y, Cruz MJD, Min Q, et al., 2013, Conserving Agricultural Heritage Systems Through Tourism: Exploration of Two Mountainous Communities in China. Journal of Mountain Science, 10(6).

[9] Sun Y, Timothy DJ, Wang Y, et al., 2019, Reflections on Agricultural Heritage Systems and Tourism in China. Journal of China Tourism Research, 15(3). 
[10] Wei N, 2019, Develop Tourism While Protecting Landscape Agricultural Heritage: A Case Study of Longji Terraced Rice Fields in Longsheng, Guangxi Province. Journal of Agricultural Management Institute of Ministry of Agriculture and Rural Affairs, 10(03): 73-78.

[11] Sun Y, Zhang C, Gao H, 2020, Conservation and Development of Hainan's Agricultural Heritage from Ecotourism Perspective: A Case Study of Haitang Bay Paddy Field National Park. Marketing Circle, 23(04): 13-14.

[12] Liu J, Shen S, 2020, Research on the Conservation and Tourism Development of Mulberry Plot-Fish Ponds in Huzhou, A Globally Important Agricultural Heritage. Modernizing Agriculture, 42(11): 5760.

[13] Su Y, Sun Y, Min Q, et al., 2019, Exploring Tourism Management Mode in Villages of China's Agricultural Heritage Sites. Chinese Journal of Agricultural Resources and Regional Planning, 40(05): 195-201.

[14] Zhang C, Min Q, Zhang H, et al., 2107, Analysis on the Rural Households Livelihoods Aiming at the Conservation of Agricultural Heritage Systems. China Population: Resources and Environment, 27(01): 169-176.

[15] Yu S, 2015, Exploring Ways to Develop Cultural Tourism with Jasmine Tea in Fuzhou. Journal of Yangtze University (Natural Science Edition), 12(09): 32-35.

[16] Lin L, Zeng F, 2016, Research on the Strategy to Develop Leisure Agriculture in Fuzhou Jasmine Agricultural Heritage Site. Rural Economic and Science-Technology, 27(23): 110-112.

[17] Guo L, 2016, Protecting Fuzhou Jasmine and Tea Culture System, Co-building a Better Fujian Province. Chinese \& Foreign Entrepreneurs, 33(25): 50-52.

[18] Hou Y, 2019, SWOT Analysis on the Development of Jasmine Tea Tourism in Fuzhou. Agricultural Archaeology, 39(02): 94-97.

[19] Fuzhou Yearbook Compilation Committee, 2018, Fuzhou Yearbook, The Straits Publishing \& Distributing Group, Fujian.

[20] Shu X, Gao Y, Yang C, 2015, Coupling Relationship and Coordinative Development Between Tourism Industry and Eco-civilization City. China Population: Resources and Environment, 25(03): 82-90.

[21] Sun J, Li S, Qin W, et al., 2019, Coupling Analysis and Optimization of Cultural Resources Endowment and Tourism Industry in Shandong. Economic Geography, 39(08): 207-215.

[22] The People's Government of Fuzhou, 2014, Regulations on Jasmine Tea Protection in Fuzhou. http://www.fuzhou.gov.cn/

[23] Chen W, Xia J, 2007, An Optimal Weights Combination Method Considering Both Subjective and Objective Weight Information. Mathematics in Practice and Theory, 37(01): 17-22.

[24] Wang S, Li M, 2015, Agricultural Heritage Research in China, China Agriculture Press, Beijing, 1925.

[25] International Exchange Service Center, Ministry of Agriculture and Rural Affairs of China, 2020, Rural Revitalization and Agricultural Heritage: Report on China Nationally Important Agricultural Heritage Conservation and Development (2019), Beijing, 49-63.

[26] Cong X, 2019, Expression and Mathematical Property of Coupling Model, and Its Misuse in Geographical Science. Economic Geography, 39(04): 18-25.

[27] Wang S, Kong W, Ren L, et al., 2021, Research on Misuses and Modification of Coupling Coordination Degree Model in China. Journal of Natural Resources, 36(03): 793-810. 